\title{
12 \\ USES AND MISUSES \\ OF EPIDEMIOLOGY
}

\author{
ALISTAIR WOODWARD
}

\section{Abstract}

Tony McMichael was at the centre of an important debate in the 1990s about the scope and range of epidemiology. His own research included both influential traditional risk factor-oriented studies and paradigm-shifting investigations of large-scale environmental and social issues. One of the best examples of effective 'micro-epidemiology' is work done on the health effects of passive smoking. Tony contributed as a researcher, a commentator and an expert witness. Among all the legal challenges to the tobacco industry, notable is the case of the Australian Federation of Consumer Organisations (AFCO) versus the Tobacco Institute of Australia (1988-90). This action in the Australian Federal Court tested the Tobacco Institute claim that 'there is little evidence, and nothing which proves scientifically that cigarette smoke causes diseases in non-smokers'. What was at stake was the status of epidemiological research; what were debated before the presiding judge, Justice Morling, were the uses and misuses of epidemiology. Tony McMichael was the principal witness for the AFCO. His testimony on the current knowledge and appropriate interpretation of epidemiological studies of passive smoking was critical to the outcome of the case, and in turn, Morling's judgement set the direction for tobacco control in Australia in succeeding decades.

\section{Introduction}

This chapter is concerned with Tony McMichael's contribution to epidemiology, the study of diseases and their causes in populations. I do not attempt to tell the full story - there is not space, and I know that others will have more to say elsewhere in the book. I will focus on epidemiology close up, research 
into environmental and behavioural factors that are proximal to the disease of interest. This is 'micro' epidemiology, as distinct from the study of the big picture phenomena that are high up in the causal chain.

I will tell of one court case, of great importance to public health, that hinged on the interpretation of micro-epidemiology, and in which Tony McMichael was at the centre.

\section{Background - The Development of Modern Epidemiology}

Origins are personal constructs. For me, modern epidemiology begins in 1957, the year in which Jerry Morris's book, The Uses of Epidemiology, was published. It was the first text to consider seriously the application of epidemiology to health problems other than infectious diseases (Smith, 2001). The book was very popular and the third edition (Morris, 1975) was my entry to public health studies in the late 1970s. The style was informal, the examples surprising, and the text fizzed and darted in unexpected and telling directions. The Uses of Epidemiology, like its author, aged extraordinarily slowly. (I met Jerry Morris only once, at Tony and Judith's house in North London, in the early 2000s. I remember him as a small man, full of good humour and bounce, even though he was into his 90s. Recently, he had been forced to give up his daily swim, Jerry told me, because every time he started on his ten laps of the local pool, the lifeguards would dive in and save him.)

I was captured immediately. Here was a book that laid out all the wonderful things that could be done with epidemiology. Not only could the epidemiologist turn her or his hand to an almost limitless number of health issues but also the ways of working were multivalent - there was potential here to connect with sociologists, economists, clinicians, biomedical scientists. Morris applied this catholic approach in his own work, which stretched from malaria control in India in World War II to the effects on the heart of regular physical activity (Morris et al., 1953; Blair and Morris, 2009), to the question of a minimum healthy wage (Morris et al., 2000).

But for some, the Morris free-range conception of epidemiology was too easy and breezy. It was not just a matter of where we wanted to go, people argued, but how to get there. What exactly was there under the epidemiological bonnet? If you listened carefully, the action seemed to run a little rough. Was it time for some fine-tuning, perhaps even a major overhaul? 
It was not the case that Morris ignored methods - he argued frequently that epidemiology's contribution depended on a critical and methodical approach to population health. But Morris foregrounded the applications of the discipline, and he drew on a wide range of techniques. As Nancy Krieger commented, 'the challenge was to think big and small at the same time; to see the details of disease mechanisms while not losing sight of the social production of disease' (Krieger, 2007).

In the last quarter of the 20th century, attention was paid, increasingly, to methods, and in particular to the methods of micro-epidemiology. This was illustrated among the textbooks by classics such as Modern Epidemiology (Rothman, 1986), and subsequently, a multiplication of subspecialty volumes, including Molecular Epidemiology (Schulte and Perera, 1998). Tony McMichael made important contributions to the technical literature. There was, for example, his early work in North Carolina on aspects of occupational epidemiology, including an elegant dissection of standardised mortality ratios that launched the 'healthy worker effect' (McMichael, 1976).

The epidemiological engine certainly did operate more strongly and more reliably as a result of these methodological improvements. But did a sharper focus in epidemiology entail limiting the field of vision?

Ken Rothman and colleagues put the case for a restricted version of epidemiology (Rothman and Poole, 1998; Rothman et al., 1998). They argued the most rapid gains came from the study of disease mechanisms in individuals. In their account, better knowledge of the fine detail of exposures and disease outcomes is the best way to reduce error, increase precision and identify health interventions.

Rothman et al. were arguing for microscope epidemiology. In their world-view, poverty and other upstream factors were not unimportant, it was just that they were out of range. Instead, they believed the discipline was most profitably employed close to disease occurrence, identifying proximal causes such as specific nutrient deficiencies, or particular carcinogens in the workplace, or pathogens that might provide the basis for effective vaccines.

Proponents of a broader view of the scope of epidemiology included Neil Pearce (Pearce, 1996), Steve Wing (Wing, 1998) and Tony McMichael. They argued that an exclusive 'close to disease occurrence' focus missed an important part of the public health picture. After all, there are epidemiological equivalents of 'failing to see the wood for the trees'. There are qualities of populations, such as levels of immunity to infectious disease, that affect the risk of ill health and may be overlooked if epidemiological studies concentrate downstream. It is not true that a finer scale of resolution necessarily takes us closer to the 
truth (Susser, 1998) and preoccupation with narrowly defined error reduction, risked in Tony's terms, making the epidemiologist a 'prisoner of the proximate' (McMichael, 1999).

An alternative approach is to work on the scale of analysis that makes most sense for the particular problem at hand. In place of microscopes, the appropriate metaphor might be spectacles with a variable focal length. It would be daft if prevailing methods determined what epidemiology did and did not pay attention to - surely, there should be some flex in the discipline's methods, to accommodate the most pressing issues of the time. Within limits, of course, epidemiologists will never have a great deal to offer particle physics, the fine detail of macroeconomics, or the important question of how to grow a broccoli that is both cancer preventing and tastes good. But, assuming a relatively broad field of operation, and depending on need, Tony McMichael and colleagues were arguing, the focus of our craft might range from chromosome to continent, from molecule to meta-analysis, from healthy worker to healthy planet.

At a micro level, there is a host of local, direct-acting toxic exposures that affect individuals. At the whole community level, there are problems such as air pollution from motor vehicles and power generation. Moving upscale, there are issues such as acid rain and brown haze. When planetary systems are affected, the problem takes on a global dimension - climate change is one example.

In other chapters, colleagues will populate the far reaches of the epidemiological matrix, reflecting on the meso and macro topics that Tony had been most concerned with recently. But here, I will concentrate on a near-field topic, environmental tobacco smoke, or passive smoking. This is partly for completeness - Tony's career spanned all the levels that have been mentioned here, and it would be a serious omission if the Festschrift neglected his important contributions to the traditional heartland of environmental epidemiology. I have chosen passive smoking because this is a success story, in which public health advances depended to a large extent on the knowledge provided by epidemiological research.

And this is also the topic that I first worked on with Tony, as a PhD student, when he and Bob Douglas were my supervisors.

\section{The Case Against Passive Smoking}

Progress towards the control of passive smoking was not straightforward. The road blocks and obstructions, the challenges, both personal and professional, are illustrated by one important case in law. This is AFCO versus the Tobacco Institute of Australia. 
On 1 July 1986, the Tobacco Institute of Australia, the public relations arm of the tobacco industry, published an advertisement in 14 Australian newspapers, entitled 'A message from those who do ... to those who don' $t$ '. The institute assumed to speak on behalf of all those who smoked cigarettes, and aimed to reassure non-smokers that their concerns about the effects on health of second-hand smoke were unfounded. 'Often our [sic] own concerns about health can take an unproven claim and magnify it out of all proportion; so that what begins as a misconception turns into a frightening myth.' The solution proposed was common courtesy: smokers should be more considerate of the annoyance that may be caused, and non-smokers should be more tolerant, taking into account 'each other's rights and feelings'.

The advertisement anticipated two significant events: the public launch of the first report from the Australian National Health and Medical Research Council (NH\&MRC) on the health effects of passive smoking (National Health and Medical Research Council, 1987), and the biennial conference of the Australian Labor Party, at which it was known a resolution would be tabled to ban smoking on all public transport, including airlines. The Labor Party was in government at the time, and if the resolution was passed, it would likely be translated into legislation (Chapman and Woodward, 1991).

The sticking point in the advertisement was the claim: 'there is little evidence, and nothing which proves scientifically that cigarette smoke causes diseases in non-smokers'. This conclusion was based, allegedly, on work from the World Health Organization, the American Cancer Society and the UK Institute of Cancer Research.

Advocacy groups responded angrily, through letters and press releases, pointing out that the relevant science was seriously misrepresented. The Australian Council on Smoking and Health took a case to the Advertising Standards Council, and gained a partial retraction from the tobacco industry.

But the most substantial challenge came, unexpectedly, from AFCO, which took its concerns to the Federal Trade Practices Commission. The Trade Practices Commission was the body responsible, among other duties, for discouraging deceptive and misleading advertising, and it ruled that this particular advertisement was not acceptable, in its original form. But AFCO was not satisfied. It sought an undertaking that the Tobacco Industry of Australia (TIA) would not repeat its claim 'that there is little evidence and nothing which proves scientifically...'. The TIA did not agree, so AFCO took action in the Federal Court. 
The case was a long-running and expensive saga - it has been estimated the TIA spent about A $\$ 5$ million on legal fees and expenses for witnesses. It was heard by Justice Morling, who was well known at the time for his role in the royal enquiry into the death of Azaria Chamberlain. (This enquiry was based on a re-evaluation of the scientific evidence, and led to the acquittal of Lindy Chamberlain.)

Before Morling, on behalf of AFCO, appeared toxicologists (Bernard Stewart), clinicians and a royal cast of epidemiologists. Tony McMichael was central to the case, as he had chaired the NH\&MRC report. He was quizzed closely by Morling on the contents of the report, and the judge was evidently impressed by the answers he received. ('I formed the opinion' he wrote in his judgement 'that Professor McMichael is highly skilled and that his opinions are entitled to great respect' (Everingham and Woodward, 1991).)

The QC for the tobacco industry was predictably hostile and pressed for any opportunity to undermine and discredit the expert witnesses on the other side. For instance, he attempted to show that Tony had a close relationship with the advocacy group, Action on Smoking and Health (ASH), and therefore could not be regarded as an unbiased witness. As part of this inquisition, Tony was ordered to supply lecture notes and teaching materials so the legal team for the TIA could comb through them in search of incriminating references. This was the day of the overhead transparency - kilograms of paper and plastic sheets were retrieved from filing cabinets and delivered to the court. (Nothing came to light that could be used against the AFCO case.)

The witnesses who appeared for the TIA were mostly imported from the USA and, on the whole, did not impress Justice Morling. For instance, the judge said of Layard, a consulting statistician, 'plainly he has a close association with the tobacco industry and depends on it for most of his income... I do not think that Dr Layard expressed opinions that he does not hold, but I do think his hyper-critical approach to the epidemiological studies may not be disassociated with his close connection with the tobacco industry'. The industry witnesses were statisticians, or toxicologists; they did not include a single epidemiologist.

The court sat for 90 days; the judgement, when it was handed down almost five years after the offending advertisement, ran to over 200 pages (Everingham and Woodward, 1991). It covered a host of contentious scientific issues that were relevant to AFCO's case. I will pick out just a couple.

Relevant evidence - when we call on the authority of science, what data are admissible? Do peer-reviewed studies have precedence? What weight (if any) should be given to the grey literature? These questions, familiar to all of us who have been involved in contentious assessments, were explored in court. 
The industry argued that meta-analyses and other forms of review should be discounted - that the relevant research included only the primary, empirical studies, and that these had to be treated one by one. The AFCO case was built on what Morling called a 'mosaic' approach to science, with constituents building up a picture that was greater than the sum of its parts. This approach, the AFCO version, was the one the judge preferred.

The starting point for the industry was that observational studies, of any kind, were not persuasive, on the basis that 'if science is the sun, statistics are Pluto'. This expression is not found in the judgement, but I think it represents fairly the arguments that were tabled before Morling.

The full quote runs:

We really don't know whether the statistical associations identified through epidemiology are real or not. After all, we've only identified them through statistics, and statistics are not science. If science is the sun, statistics are Pluto. In fact, all sorts of wacky associations can be identified through statistics.

And the source is Steve Milloy, at the website junkscience.org. Milloy was not involved with the AFCO case, as far as I know, but his name is familiar to those who have studied the 'merchants of doubt', and the argument that association is not the same as cause has been launched against epidemiology on many occasions (Oreskes and Conway, 2010). It gained no purchase here. Nor did a subsequent foray from industry trenches, brandishing statistics in the form of significance testing and arguing that $p$ values were pass/fail arbiters of causal validity.

In hindsight, the TIA would have been in a much stronger position if the advertisement had said no more than 'nothing that proves scientifically'. To claim 'there was little evidence' put the industry in a very exposed position, and Morling's finding was unambiguous. 'There is compelling scientific evidence' he concluded 'that cigarette smoke causes lung cancer in non-smokers', and 'the evidence establishing a causal relationship between passive smoking and respiratory disease in very young children is overwhelming. The evidence is of such strength that it constitutes scientific proof' (Everingham and Woodward, 1991). To rub salt into the wound, he ordered the TIA to pay the costs of the other side.

What were the consequences of the Morling judgement? It carried political weight, for a start. The tobacco industry's expert witnesses had performed woefully in court, and the credibility of the industry took a dive. Remember 
this was the 1980s and '90s, when tobacco companies had not yet fallen to pariah status - respectable universities still accepted industry money for what it, the university, believed was honest medical research with no strings attached.

The judgement affirmed the value of epidemiology in sorting out difficult, contested environmental problems, and it contained a very useful summary of the science that was being debated at the time. But perhaps what was most important was that Morling was a springboard for regulation, policy and a large-scale shift in public attitudes to tobacco. Other factors played a part, of course, but the Morling judgement skewered the argument that 'common courtesy' would suffice, and provided the foundation for intervention. There were questions still about how much ill health could be attributed to this cause, but not about whether second-hand smoke was harmful.

It is easy to forget how much has changed. In the late 1980s, smoke-free policy in Australia (and other countries) was partial, ineffective and apologetic. Twenty years post-Morling, in Australia and many other parts of the world, policies are comprehensive, widely accepted and assertive (International Agency for Research on Cancer, 2009).

There have been important advances also in the epidemiology of passive smoking. For a start, the quantity of evidence has increased manyfold. When the TIA advertisement appeared, claiming 'little evidence that cigarette smoke causes disease in non-smokers', there were fewer than a dozen studies of lung cancer and passive smoking. A review published in 2001 counted 43 epidemiological studies of this kind (Taylor et al., 2001). More important than the mushrooming number of studies is the consistency of the findings: the odds of lung cancer among non-smoking women married to men who smoked did not change materially between 1987 and 2001, although the statistical uncertainty around the pooled estimate has reduced considerably.

At the heart of the objections raised before Morling by the TIA was the issue of biological plausibility. How could it be, witnesses for the industry asked, that such small exposures, compared with the amount of smoke inhaled by an 'active' smoker, caused such large effects? The disjunction between dose and outcome seemed particularly large with cardiovascular diseases. A woman who smoked 10-15 cigarettes a day increased her risk of a heart attack by about 100 per cent; for the non-smoking wife of a man who smoked, the excess risk was roughly 30 per cent, although she breathed in much less than one-third of the dose of toxic agents in tobacco smoke. Research carried out in the last 20 years has solved this puzzle. Clinical studies have demonstrated clearly the ways in which second-hand smoke affects the heart and blood vessels, and epidemiology has filled in the gaps in the dose-response curve. The findings of the early studies on second-hand smoke are not inconsistent with the research on active smoking, 
because the nature of the dose-response is non-linear. What were thought to be 'small' exposures to tobacco smoke were clearly sufficient to bring about potentially dangerous changes such as vascular inflammation and increased platelet activity. However, these biological responses are saturated or buffered in some way at higher doses, and if graphed on a linear scale, the dose-response curve flattens out in the active smoking range (Pope et al., 2009).

The arguments before Morling focused very much on lung cancer - much less attention was paid to other diseases that might be related to second-hand smoke. But subsequent work on the burden of ill health attributable to passive smoking has shown that cases of lung cancer are a small proportion of the total. It has been estimated that in 2004, worldwide, 40 per cent of children, 33 per cent of male non-smokers and 35 per cent of female non-smokers had been exposed to second-hand smoke (Öberg et al., 2010). This exposure was estimated to have caused, each year, about 21,400 deaths from lung cancer (about 3.5 per cent of all mortality attributable to second-hand smoke). Much more numerous were 379,000 attributable deaths from ischaemic heart disease, 165,000 from lower respiratory infections and approximately 36,900 from asthma.

Although the burden of disease due to passive smoking remains considerable, worldwide, there have been significant advances. One of the most important has been the introduction in many countries of comprehensive smoke-free policies in the workplace. These policies have been shown to reduce the prevalence of smoking at work, and to cut exposures to second-hand smoke dramatically. (In New Zealand, it was estimated that smoke-free laws reduced exposures in bars and hotels by 90 per cent (Fernando et al., 2007).) What has also become apparent is that laws of this kind have substantial beneficial and rapid effects on public health. Up to 2009, there were nine studies published on the effect of smoke-free legislation on hospital visits for acute coronary disease. What was seen was a reduction of 15-20 per cent in the first 12 months after legislation, consistent with falling exposures to second-hand smoke in the workforce and in the population at large, and it was unlikely that this effect could be explained by other changes that took place at the same time as smoke-free laws were introduced (International Agency for Research on Cancer, 2009).

\section{Conclusion}

For his 1999 paper, Tony drew a figure to illustrate the dimensions in which epidemiology might operate (Figure 12.1). He argued that we should think adventurously, beyond common presumptions, which tend to huddle in the 
bottom left-hand corner of the picture. (And for good reason - look at the far right-hand corner - doing epidemiology in the future? Goodness, that is a big ask.)

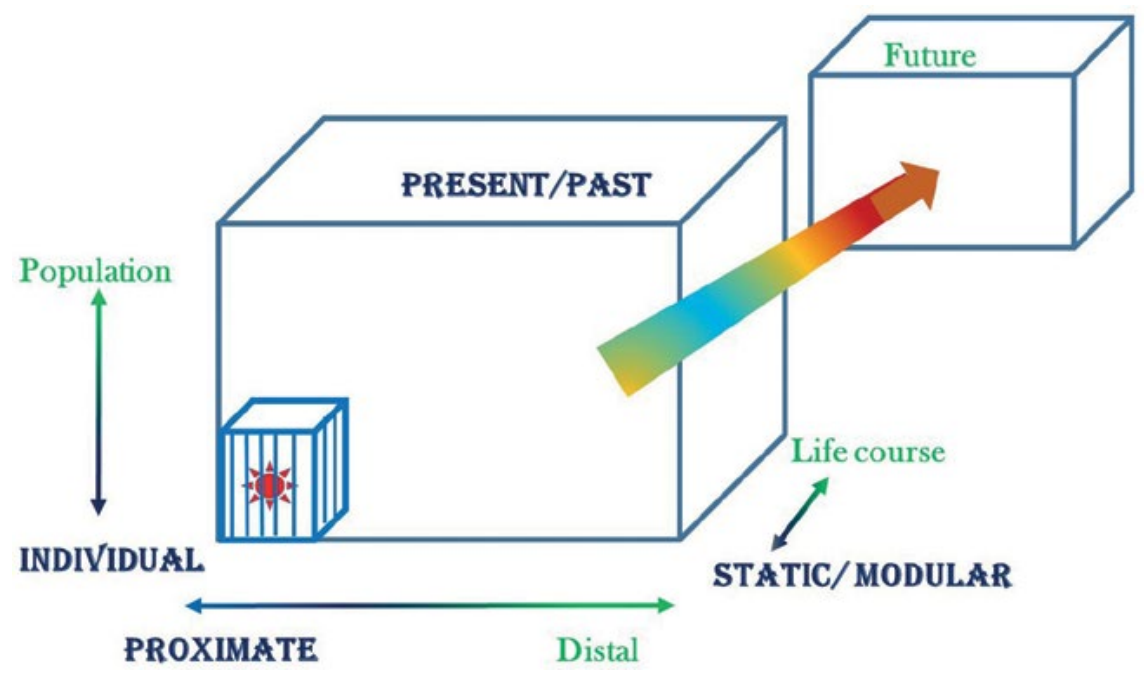

Figure 12.1 The dimensions of epidemiological research.

Source: McMichael, 1999 (redrawn with permission from Oxford University Press).

The zone of comfort is marked by what could be a jail cell containing a crystal ball, or a child's playpen with a beach ball. Tony was at pains to defend the use of proximal epidemiology, where it was appropriate, and passive smoking was one case in which the bottom left-hand corner was the right place to be. But he urged us: if the need arises, leave the playpen, because purpose trumps technique.

To my mind, Tony McMichael and Jerry Morris were very much on the same page. 'One of the urgent needs of highly developed and rapidly changing societies', Jerry Morris wrote in his textbook, 'is to determine ways of healthy living, the wisdom of body and mind and the principles of social organization that can inform the quality of life and lighten the burden of disease. The quest for this knowledge is the main use of epidemiology.'

\section{References}

Blair, S.N. \& Morris, J.N. 2009. Healthy hearts - and the universal benefits of being physically active. Annals of Epidemiology 19, 253-6.

Chapman, S. \& Woodward, S. 1991. Australian court rules that passive smoking causes lung cancer, asthma attacks, and respiratory disease. BMJ 302, 943-5. 
Everingham, R. \& Woodward, S. 1991. Tobacco Litigation. The Case Against Passive Smoking AFCO v TIA. Legal Books, Sydney, New South Wales, Australia.

Fernando, D., Fowles, J., Woodward, A., Christophersen, A., Dickson, S., Hosking, M., et al. 2007. Legislation reduces exposure to second-hand tobacco smoke in New Zealand bars by about 90\%. Tobacco Control 16, 235-8.

International Agency for Research on Cancer 2009. IARC Handbooks of Cancer Prevention, Tobacco Control, Vol. 13: Evaluating the Effectiveness of Smokefree Policies. IARC, Lyon, France.

Krieger, N. 2007. Commentary: Ways of asking and ways of living: reflections on the 50th anniversary of Morris' ever-useful Uses of Epidemiology. International Journal of Epidemiology 36, 1173-80.

McMichael, A.J. 1976. Standardized mortality ratios and the 'healthy worker effect': scratching beneath the surface. Journal of Occupational Medicine $18,165-8$.

McMichael, A.J. 1999. Prisoners of the proximate: loosening the constraints on epidemiology in an age of change. American Journal of Epidemiology $149,887-97$.

Morris, J.N. 1975. The Uses of Epidemiology. Third Edition. Churchill Livingstone, London, UK.

Morris, J.N., Heady, J.A., Raffle, P.A., Roberts, C.G. \& Parks, J.W. 1953. Coronary heart disease and physical activity of work. The Lancet 265, 1053-7.

Morris, J.N., Donkin, A.J.M., Wonderling, D., Wilkinson, P. \& Dowler, E.A. 2000. A minimum income for healthy living. Journal of Epidemiology \& Community Health 54, 885-9.

National Health and Medical Research Council 1987. The Heath Effects of Passive Smoking. A Scientific Information Paper. NH\&MRC, Canberra, ACT, Australia.

Öberg, M., Jaakkola, M.S., Woodward, A., Peruga, A. \& Prüss-Ustün, A. 2010. Worldwide burden of disease from exposure to second-hand smoke: a retrospective analysis of data from 192 countries. The Lancet 377, 139-46.

Oreskes, N. \& Conway, E.M. 2010. Merchants of Doubt. How a Handful of Scientists Obscured the Truth on Issues from Tobacco Smoke to Global Warming. Bloomsbury Press, New York, USA.

Pearce, N.E. 1996. Traditional epidemiology, modern epidemiology and public health. American Journal of Public Health 86, 678-83. 
Pope, C.A. 3rd, Burnett, R.T., Krewski, D., Jerrett, M., Shi, Y., Calle, E.E., et al. 2009. Cardiovascular mortality and exposure to airborne fine particulate matter and cigarette smoke. Shape of the exposure-response relationship. Circulation 120, 941-8.

Rothman, K.J. 1986. Modern Epidemiology. First Edition. Little, Brown and Company, Boston, Massachusetts, USA.

Rothman, K.J. \& Poole, C. 1998. Our conscientious objection to the epidemiology wars. Journal of Epidemiology \& Community Health 52, 1-2.

Rothman, K.J., Adami, H.-O. \& Trichopoulos, D. 1998. Should the mission of epidemiology include the eradication of poverty? The Lancet 352, 810-2.

Schulte, P.A. \& Perera, F.P. (eds) 1998. Molecular Epidemiology. Principles and Practices. Academic Press, Boston, Massachusetts, USA.

Smith, G.D. 2001. The uses of 'Uses of Epidemiology'. International Journal of Epidemiology 30, 1146-55.

Susser, M. 1998. Does risk factor epidemiology put epidemiology at risk? Peering into the future. Journal of Epidemiology \& Community Health 52, 608-11.

Taylor, R., Cumming, R., Woodward, A. \& Black, M. 2001. Passive smoking and lung cancer: a cumulative meta-analysis. Australian \& New Zealand Journal of Public Health 25, 203-11.

Wing, S. 1998. Whose epidemiology, whose health? International Journal of Health Services 28, 241-52. 
This text is taken from Health of People, Places And Planet:

Reflections based on Tony McMichael's four decades of contribution to epidemiological understanding, edited by Colin D. Butler, Jane Dixon and Anthony G. Capon, published 2015 by ANU Press, The Australian National University, Canberra, Australia. 